Introduction

NWALL: Northwest (AK, WA, OR, MT, ID)

\section{Regional News}

\section{LeeAnn Stone University of California-Irvine}

What's up-why am I reporting this column? Well, in December, the IALL Board decided to "call in the reserves" to help fill in some gaps that Robert Henderson's passing had created in the organization. Nina Garrett has moved to take over the role of President, and the Board called upon several "old timers," myself among them (Is that really where I am in life now?!), to temporarily cover critical communications and project areas. This is the area they asked me to coverthat of communicating with the Regional Leaders regarding activities, conferences and projects, and getting that information back out to you, the IALL member.

I'm only here temporarily; I hope to introduce the new IALL President-Elect to each of the regional leaders and their activities before the conference in August so that $s /$ he can present this report to you in a future Journal issue. This isn't an assignment that I am necessarily in any hurry to relinquish, though; it's been fun renewing my acquaintance with the personalities and professional activities of dynamic IALL members from across the country. So in the short term, and until our new President-Elect is in place and working fullsteam for IALL, feel free to forward suggestions, notes or other information to me. In the meantime, relax and enjoy the following regional tour!

News from the Northwest Region is that "things will hopefully get moving in the Spring." This comes from Paul Aoki, the region's new leader. The Northwest does have a web page, which is almost ready for publication on "the big screen" (the IALL web page, that is!).

While this region has not yet held a meeting this academic year, they will have a chance to gather at FLEAT III/IALL 97 in Victoria. More information on the regional meetings will be published in the conference program. 
Leader: Paul K. Aoki

Language Leaning Center

University of Washington

108 Denny Hall

Box 353140

Seattle, WA 98195-3140

(206) 543-0536

i5no8@u.washington.edu

SALT: Southwest
(CA, NV, AZ, HI)

Kansai Gaidai Hawaii College)

Punahou School

Honolulu Community College

The University of Hawaii-Manoa
The Southwest regional group (SALT) held a conference over Thanksgiving week in Hawaii. Hosted by Jose Cachuela (Kansai Gaidai Hawaii College), Daniel Tom (University of Hawaii-Manoa), and Fawn Whittaker (Brigham Young University-Hawaii), the three-day-plus conference gave attendees the opportunity to visit six different and quite diverse campuses.

The first afternoon's welcome reception and business meeting was held at Kansai Gaidai Hawaii College (KGHC). Attendees were able to informally visit the language and technology facilities of this two-year college which preps Japanese students for entrance as juniors into U.S. universities.

Wednesday morning took members to Punahou School, the oldest college preparatory school west of the Rockies. Punahou, which has an enrollment of 3700 students and a faculty of 260 , is extremely rich in technology infrastructure, support and utilization. Hope Kuo Staab, Co-Director of the Wo International Center, provided attendees with a tour of the many labs and other resource centers on the campus. It did make some of us blush (myself included!) at the insufficiencies in our own university facilities!

Our next stop was Honolulu Community College, which provides an "Associate Degree of the Air" for a number of their highly rated technical training programs. Ramsey Peterson, Dean of Instruction, and John Blumhardt, Director of the Educational Media Center, discussed with us this modularized, performance-based vocational training model in which 1000 students are enrolled each session, which is a five-fold increase over the total enrollment of all three of Oahu's Community Colleges combined.

Daniel Tom hosted Friday morning's sessions at the University of Hawaii at Manoa. Presentations included: 
- Un Meurte à Cinet (Un homicidio en Toluca)-an email whodunnit to develop writing competence in intermediate level language classes offered at a distance (Walter Oliver, CSU-San Bernardino)

-SMARTBoard Demonstration and Discussion (Scott Tamura, Honolulu Audio and Video)

-Autogloss Demonstration-downloadable software for translation of kanji in the reading of Japanese texts (David Ashworth, UH-Manoa)

- Wenlin Demonstration-software for look-up of Chinese characters (Daniel Tom, University of Hawaii-Manoa)

Hawaii Pacific University

Brigham Young University-Hawail
Friday afternoon's meeting, hosted by Barbara Voigt, Director of HPU's Learning Assistance Center, included a tour of HPU's Technology Classroom and Multimedia Production facility, and presentations and demonstrations of hardware (Tanderg's Virtual Tape Recorder), software (Blackbelt Japanese and Language Teaching CD-ROMs), and discusion of planning and managing a lab ("Experiences with Multimedia on a Windows NT Network" and "Retrofitting Classrooms for Educational Technology") among many others.

The final meeting of the conference was held Saturday morning at BYU-Hawaii. Fawn Whittaker hosted this segment which included sessions on the CATS checkout and inventory program; a Powerpoint "Orientation to the LC" demonstration; "Aspects for Interactive Composition", "Low Tech for High Brows", a demo of Apple's World Language Kits; and several other presentations.

When the conference ended Saturday afternoon, attendees and their friends and families met at the Polynesian Culture Center (a part of BYU-H) and spent the afternoon and evening enjoying the sights, sounds, tastes, colors, humor, and culture of the peoples of Polynesia.

SALT's next meeting was set for Friday and Saturday, May 9th and 10th, at UC Berkeley, hosted by Mark Kaiser.

Leader: Renate Albrecht

Stanford University

Meyer Library

Stanford, CA 94305 USA

(415) $725-5523$ 
M-SALT: Rocky Harold Hendricks has led this group for the past several Mountain (CO, years while also trying to hold down the duties of Journal WY, NM, UT Advertising Manager-in short, he's looking for someone else to pick up this ball and get it rolling! The Rocky Mountain Region is really the "wild west" of IALL-distances are great, and there does not exist the concentration of institutions that are found in other areas of the country-so this can be an exciting challenge to take on for someone interested in getting more involved with IALL and with colleagues in his/her region. If you're interested, feel free to contact Harold.

Leader: Harold Hendricks

Humanities Research Center

Brigham Young University

3060 JKHB

P.O. Box 26098

Provo, UT 84602-6098

(801) 378-6448

harold@jkhbhrc.byu.edu

MWALL: Midwest (ND, SD, NE, KS, MN, IA, MO, WI, IL, OH, MI, IN)
The following announcement is excerpted from Jacqueline Kaminski's posting on LLTI:

Wabash College will host the Spring MWALL Conference, "Searching for Solutions," April 11 and 12, 1997. The goal of this conference is to bring faculty, lab, and tech directors together to explore opportunities afforded by the use of multimedia in the classroom or language lab. Particular focus will be placed on solutions which address individual or collaborative development of materials, intra- or internet use, innovative uses of multi-media, distance learning, and other related ideas.

The conference is designed to address all levels of expertise, from beginner to advanced. Participants will be able to talk with technical experts, as well as other faculty members, and activities will range in focus from hands-on work to discussions and presentations. There will be something for everyone with an interest in educational technology applications and languages.

A call for presenters and more info on the conference is available at the MWALL website at: http:// LanguageCenter.cla.umn.edu/MWALL/.

Another note of interest from the MWALL group: They are in the process of compiling a regional conference handbook to provide "dos and don'ts", including organizational and planning tips, for pulling together a regional meeting. Ron Balko, Marlene Johnshoy, Pam Castro 
and Charlotte Wharton are involved in this project, and Charlotte is also chairing a workshop/roundtable on conference planning (from local to regional to national conferences) at FLEAT III/IALL 97.

Ron Balko, current MWALL leader, also made the recommendation that regional leaders have a scheduled opportunity to meet as a group at FLEATIII/IALL '97. So, in addition to the scheduled regional group meetings that we all look forward to at our IALL conference, the planning committee is also arranging for the regional leaders to get together. Keep your eyes out for the conference program for more information on these two sets of meetings.

\section{Leader: Ron Balko, Director \\ Instructional Media Services \\ Concordia College \\ Moorhead, MN 56562 \\ (218) 299-3464 \\ balko@gloria.concordia.edu}

SOCALL: South Central (TX, OK, AR, LA)
Pete Smith, SOCALL leader, reports that the organization has been to this date Texas-centric, but that this is changing. Their once-a-year-in-the-Spring meeting will be held at the University of Arkansas in Little Rock this year. This strategically-planned meeting will take advantage of the fact that the Arkansas Foreign Language Teachers are congregating there at this time also. SOCALL has its meeting for the following year already planned out as well it will likely be held in Louisiana.

Pete has several clever ideas to share with the IALL membership in general-for one, he wants all to know that his campus is only minutes away from D/FW International, and he encourages folks to contact him if they have a long layover ( $2-3$ hours) planned there. Pete informed me that some of his most productive and interesting meetings have been with IALL folks that he has met at the airport!

Pete reports that SOCALL is doing well financially, and the organization is discussing ways that they can constructively use these funds. One idea includes providing small stipends to graduate students. Do any of the other regions do anything like this? If so, SOCALL would like to hear from you.

Finally from SOCALL-Claire Bartlett will take over as regional leader at the upcoming Spring meeting. With this Journal issue coming so close to this transition, I am providing her name below as your contact with this group. 
Leader: Claire Bartlett

Language Lab

University of Houston

AH, Room 311

4800 Calhoun

Houston, TX 77204-3783

(713) 743-3211

hclsa@jetson.uh.edu

NERALLD: New England (ME, VT, $\mathrm{NH}, \mathrm{MA}, \mathrm{CT}, \mathrm{RI})$
The following reports intertwine several excerpts from NERALLD's most recent newsletter, and conversations and email discussions with NERALLD President, Bruce Parkhurst.

NERRALD's last meeting was held at Williams College and hosted by new-to-NERRALD member Tamra Hjermstad. In fact, the meeting she hosted was only her second NERALLD meeting ever! Reports back from this conference were so favorable, that Tamra was identified as someone who should be involved in the proposed Conference Planning Roundtable/Workshop for FLEAT III/IALL 97.

Boston University is slated as the site of NERRALD's next meeting on April 4th. Bruce Parkhurst, recently elected NERRALD President (unanimously I may add!), will host. Ruth Trometer is coordinating the presentations which will include issues of lab management built on the use of databases and other such tools; thus the theme: "Lab Management Issues."

This theme is an important one for Bruce. She feels that it is hard to keep up with the high-tech stuff without tempering it with discussion of the basic nuts and bolts that affect lab directors daily. Thus one approach she'd like to focus on is addressing the needs of smaller, understaffed and/or illequipped labs by visiting them, providing trouble shooting and strategy planning sessions, utilizing the wealth of expertise within the NERRALD group. The other issue that NERALLD will focus on under Bruce's leadership is that of motivating and involving faculty, an issue that's been a hot topic in NERRALD for years.

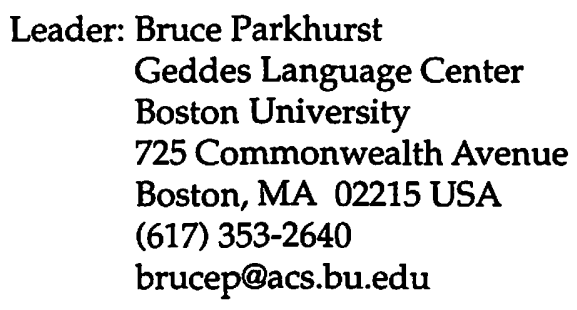

Leader: Bruce Parkhurst

Geddes Language Center

Boston University

725 Commonwealth Avenue

Boston, MA 02215 USA

(617) 353-2640

brucep@acs.bu.edu 
NEALL: Northeast (NY, PA, NJ, DE)
The following is excerpted from an LLTI posting (and edited to reflect the past tense!)

The NorthEast Association of Language Labs met at Swarthmore College March 14 to 16 with Michael Jones of the Language Resource Center as host. Friday's meeting started with an evening reception hosted by Chester Technical Services. A very full two days of sessions followed with Saturday focused on issues directed at language faculty, and Sunday addressing issues of lab management.

Saturday's program included:

- "Mellon Grant Partnerships in Language Technology Developments-Faculty Training: The Middlebury Experience." Faculty and staff from Swarthmore, Bryn Mawr, Haverford and Franklin \& Marshall who attended a Mellon Technology Workshop at Middlebury discussed their experiences. Could Middlebury serve as a model for other faculty workshops? What efforts at cooperation have emerged?

- "Implementing the Mellon Grant:-Three Perspectives: Learning Center Director, Faculty Member, Project Director" (Amale Gaffney and Thomas Harrington, Lafayette College; Robin Clouser, Ursinus College). Lafayette and Ursinus have also received a Mellon development grants to produce computer-enhanced software for classroom use. The three panel members shared thoughts about the implementation process, strategies for working in a bi-college relationship, and challenges from their three different perspectives.

- "Authentic Language Text (GALT): Penn State Project" (Mary Ann Lyman-Hager and Norval Bard, Pennsylvania State University). Authoring shells have cut time needed to create user-friendly software with built-in multimedia features. GALT has allowed content experts to annotate authentic foreign language literary text for use in undergrad language courses. The shell allows for works, phrases, or groups of words of a "page" to be hyperlinked to digital media or simple text glosses. The glossing capability of the software has permitted instructors to create in-class activities while having students read the text and prepare related contents questions out of class.

- "Un Meurtre à Cinet (Un Homicidio en Toluca): Teaching an Intermediate-Level Language Course via the Web" (Terri J. Nelson and Walter Oliver, Caifornia State-San Bernadino). The presenters described a late first-year or intermediate-level language role-playing project that 
relies on a WWW site and email murder mystery. Students work collaboratively in a linguistically and culturally rich context. A series of interactive Web pages creates the rest of the curriculum, as students perform a certain number of tasks (vocabulary and grammar) in order to earn "money" which they can spend or invest to undertake tasks (shopping for clothes, buying groceries, purchasing train tickets).

- "ClicNet, A WWW site for the Teaching of French" (Carole Netter, Swarthmore College). ClicNet is a directory of Francophone resources, both original publications and pointers to virtual resources in French. It is intended for both independent student use and for teaching French, with 1500 links from throughout the Francophone world. This session was also a workshop for French teachers on use of the Web.

- "Agora Marketplace" (Joel Goldfield, Fairfield University).

- "Multimedia and Interactivity over the WWW for Language Teaching" (William Haworth, John Moores University) This presentation reviewed what is currently available on the Web in terms of multimedia for language learning, and what developments are underway. Various pedagogical consequences, both inevitable and potential, were discussed. Questions posed included: What traditional teaching and learning paradigms are amenable to WWW delivery? Are new paradigms suggested?

- "Taking L2 Profs into the 21st Century with Technology: Insights from Learning Theories" (Diane Beelen Woody, York University) This multimedia Language Center Coordinator provided a theoretical framework for working with language faculty to overcome resistance to technology. She stressed the need for explicit instruction throughout the process of discovery for new technology users. Insights included the clear need for "validated learning" and use of concrete examples of learning theory.

Sunday's sessions focused on planning and included:

- "LRC Planning: The Swarthmore Experience," chaired by Michael Jones (Swarthmore College). Swarthmore recently opened a new LRC after a year of planning. A panel of faculty and staff reviewed the process of designing, funding and installing the lab.

- "Second Language Study Committee Planning for New 
Lab Facilities" (Robin Lawrason, Temple University). Robin reviewed language lab planning in conjunction with overall university-level technology planning ongoing at Temple University. AAHE has inspired the development of Teaching Learning Technology Round tables at colleges around the country. The Temple Technology Roundtable issued guidelines for technology plans for colleges and departments, and also reviews school and college technology goals. The importance of planning individual facilities such as language labs within an overall institutional context is stressed.

- "Equipment Replacement: Planning for Obsolescence" (Wendy Baker Davis, Kathleen Lewis, and Michael Jones). This panel discussed aging technology experiences at Franklin \& Marshall, Haverford and Swarthmore. How do you run software on older machines? How do you deal with maintenance and repair? Can you secure a budget for timely replacement of equipment?

\section{Leader: Robin Lawrason, Director \\ Media Learning Center \\ Temple University \\ Philadelphia, PA 19122 \\ (215) 204-4758 \\ lawrason@vm.temple.edu}

MAALD (NC, TN,
KY, VA, WV,
MD, DC)

MAALD's last meeting was held at Washington and Lee University in conjunction with a Culpeper-sponsored conference entitled, "Ingenious Methodologies through Language Technology". Dick Kuettner, Director of the Tucker Multimedia Center at W\&L hosted both meetings. The organization elected its new co-leaders at this time; they are Chris Higgins and Samantha Earp.

The meeting at W\&L was the first in many years, so Chris and Samantha, along with their colleagues in the region, are tackling the task of rebuilding the organization. They are taking a unique approach: they have divided the region into subregions, each with its own leader. In his subregion, for example, Chris plans to organize a round robin of local universities, visiting two institutions in one day, once a month.

Among other notes from the region:

- Samantha Earp is working on the MAALD web page.

- MAALD will hold a business meeting at ACTFL next November. 
- Chris mentions that for those of you laying over any time at Washington National, downtown D.C. is only 10-15 minutes away. A whole host of schools are located in D.C., including Georgetown, Catholic University, American University and George Mason. BaltimoreWashington International and Dulles airports are also close.

- Chris suggested that IALL create a searchable database of membership information so that instead of the Board having to provide this information to the regions, it would be there and available for look-up.

- Chris also suggested that IALL may consider future reorganization of state affiliations if needed. Both MAALD and the Southeast group have cross-over membership.

Leaders: Samantha Earp

English and Foreign Language Department
Central Piedmont Community College
P.O. Box 35009
Charlotte, NC 28234 USA
(704) 510-6876
ssearp@unccvms.uncc.edu
Chris Higgins
Foreign Language Instructional Technology
University of Maryland
Language Center
Jimenez Hall 1105
College Park, MD 20742-4811 USA
(301) 405-6927
chiggins@deans.umd.edu

Southeast (MS, AL,

The Southeast region is rolling again! Marc Mallet, Director $\mathrm{SC}, \mathrm{GA}, \mathrm{FL})$ of the Foreign Language Lab at the Lovett School in Atlanta, agreed in January to take over the leadership of this region, which has been without a leader for some time. He's not in it alone, though. Within days of accepting the position, he had already recruited his leadership team, which includes Dominique Bennett (newsletter editor), Anna Boller (regional conference coordinator) and Russel Hansen (electronic publications coordinator). Additionally, Georgia Schlau (College of Charleston) has expressed an interest in hosting the first regional conference.

What is particularly interesting about these regional leaders is that most work in a K-12 environment. $\mathrm{K}-12$ folks are a group that we long have wanted to involve in greater numbers, but 
with few such members, I believe we have not necessarily known how to reach out to them. I do think the Southeast group will help us make a start!

Leader: Marc Mallet

Foreign Language Department

Lovett School

4075 Paces Ferry Road NW

Atlanta, GA 30327 USA

(404) 262-3032

mmallet@mail.lovett.pvt.k12.ga.us

Kathy Hanneson (University of Guelph) and Annick Deakin (University of Western Ontario) have taken on the leadership of CANIALL. This is geographically the largest IALL regional group of all, with significant diversity among its constituents-Kathy and Annick have a big task ahead of them, and we appreciate their efforts! The following report is excerpted from a letter they sent in February to CANIALL members.

At the last IALL conference (May 1995 at Notre Dame) Canadian members got together at the Regional Luncheon and discussed the possibility and viability of a Canadian Regional Group. We hope to meet again at the FLEAT III/ IALL 97 conference at the University of Victoria in August 1997. In order to prepare for this discussion, we would like to gather some basic information on who is interested in such a group and what it might accomplish.

Some of us think that while our wide-spread locations may limit the possibility of face-to-face meetings, maintaining contact with each other and sharing information and ideas could have a number of benefits, for example:

- discussion on issues that we as Canadians have to deal with differently than our counterparts in other countries, such as copyright and funding sources;

- providing a Canadian perspective on various IALL committees or projects;

- increased contact among lab directors on a local level, or among those with similar interests;

- information and contacts for those wanting to consult with other facilities or undertake cooperative projects.

As a first step, Canadian members are asked to send a reply message including some brief information about yourself, a basic description of your lab or media centre facilities or other professional interests, and any comments about the potential 
usefulness of a Canadian IALL group to Kathy Hanneson at khanneso@uoguelph.ca. Also, if you know of anyone else who might be interested in being part of this Canadian group who is not an IALL member, please pass this information along.

Leaders: Kathy Hanneson

College of Arts Media Centre

University of Guelph

Guelph, Ontario

Canada

khanneso@uoguelph.ca

Annick Deakin

Language Learning Centre

University of Western Ontario

London, Ontario N6A 3K7

Canada

(519) 661-2104

deakin@julian.uwo.ca

LeeAnn Stone is Director of the Humanities Instructional Resource Center at the University of California-Irvine and a Past President of IALL. 